nursing education. Nurs Educ Perspect. 2007Sep-Oct;28(5):263-7.

14. Boozaripour M, Abbaszadeh A, Shahriari M, Borhani F. Ethical values in nurse education perceived by students and educators. Nurs ethics. 2018 Mar;25(2):253-63.

15. Lützén K, Nordin C, Brolin G. Conceptualization and instrumentation of nurses' moral sensitivity in psychiatric practice. Int J Methods Psychiatr Res. 1994. ;4(42):241-248.

16. Lutzen K, Dahlqvist V, Eriksson S, Norberg A. Developing the concept of moral sensitivity in health care practice. Nurs ethics. 2006 Mar;13(2):18796.

17. Abbaszadeh A, Borhani F, Moazen- Nematollahi L. The comparison of the level of moral sensitivity in nursing students and nursing staffs in Kerman in 1389. J Med Ethics. $2010 ; 4$ (12):39-54.

18. Karimi Noghondar M, Tavakoli N, Borhani F, Mohsenpour M. Ethical sensitivity: A comparison between the nursing students and nurses of Azad University. Iran J Med Ethics Hist Med. 2016 Feb;8(5):69-76.

19. Farasatkish $\mathrm{R}$, Shokrollahi N, Zahednezhad H. Critical care nurses' moral sensitivity in Shahid Rajaee Heart Center Hospital. Iran J Cardiovasc Nurs. 2015 Jun; 4(3) :36-45.

20. Hakim A. Nursing students' satisfaction about their field of study. $J$ Adv Med Educ Prof. 2014Apr;2(2):82-7.

21. Mills D, Alexander P. Small group teaching: a toolkit for learning. The Higher Education Academy. 2013 Mar.4-5

22. Edmunds S, Brown G. Effective small group learning: AMEE Guide No. 48 . Med Teach. 2010 Aug;32(9):715-26.

23. Aeen F, Heravi M, Ahmadi F, Tootoonchi M. Baccalaureate Nursing Curriculum: Its Adjustment with Burden of Diseases as "Disability Adjusted Life Years" in Iran. Iran J Med Educ. 2006;6(2):8-16.

24. Farsi Z, Dehghan-Nayeri N, Negarandeh R, Broomand S. Nursing profession in Iran: an overview of opportunities and challenges. Jpn J Nurs Sci. 2010 Jun;7(1):9-18.

25. Ertug N, Aktas D, Faydali A, Yalçin O. Ethical sensitivity and related factors of nurses working in the hospital settings. Acta Bioeth. 2014 Nov;20(2).

26. Kang S-W. The influence of ethics education on awareness of nursing students with no clinical experience regarding the code of ethics: A case study. Journal of Nursing Education and Practice. 2017 April; 7(10):12.

27. DeSimone BB. Curriculum design to promote the critical thinking of accelerated bachelor's degree nursing students. Nurse Educ. 2006 SepOct;31(5):213-7.

28. Johnsen HM, Fossum M, Vivekananda-Schmidt P, Fruhling A, Slettebo A. Developing a Serious Game for Nurse Education. J Gerontol Nurs. 2018 Jan;44(1):15-9.

29. Chang TP, Kwan KY, Liberman D, Song E, Dao EH, Chung D, et al. Introducing Teamwork Challenges in Simulation Using Game Cards. Simul Healthc. 2015 Aug;10(4):223-6.

30. Macer DR. Moral games for teaching bioethics: International Center for Health, Law and Ethics, Faculty of Law, University of Haifa; 2008.

31. Shahriari M, Mohammadi E, Fooladi MM, Abbaszadeh A, Bahrami M. Proposing codes of ethics for Iranian nurses: A mixed methods study. $J$ Mix Methods Res. 2016 Feb;10(4):352-66.

32. Sanjari M, Zahedi F, Aalaa M, Peimani M, Parsapoor A, Cheraghi MA, et al. Code of ethics for Iranian nurses. Iran J Med Ethics Hist Med. 2011 Sep;5(1):17-28.

33. Zahedi F, Sanjari M,Aala M,Peymani M, Aramesh K, Parsapour A, et al.The code of ethics for nurses. Iran J Public Health. 2013 Jan;42(Supple1):1-8

34. Maddineshat $M$, Hashemi $M$, Gharib $A$. The effect of implementing nursing ethics code as a combined plan, in the School of nursing and clinical setting, Bojnurd, North Khorasan Province (2013-2015). Bali Med J. 2018 April;7(1):27-34

35. Shapira-Lishchinsky O. Ethical dilemmas: the experiences of israeli nurses. Qual Health Res. 2009;19(11):1602-11.

36. Stanley D, Latimer K.'The Ward': A simulation game for nursing students. Nurse Educ Pract. 2011 Jan;11(1):20-5.

\title{
Relationship between autonomy and moral distress in emergency nurses
}

\author{
MOHSEN ABDOLMALEKI, SIMA LAKDIZAJI, AKRAM GHAHRAMANIAN, ATEFE ALLAHBAKHSHIAN, MOZHGAN BEHSHID
}

\section{Abstract}

Reducing nurses' autonomy can impair their decision-making and ability for appropriate interventions. Lowered independence

Authors: Mohsen Abdolmaleki (Mohsen_2068491@yahoo.com), MSc Student in Nursing, Student' Research Committee of Nursing and Midwifery Faculty, Tabriz University of Medical Sciences, Tabriz, IRAN Sima Lakdizaji (corresponding author --laks@tbzmed.ac.ir), Nurse Educator, Department of Medical Surgical Nursing, Faculty of Nursing and Midwifery, Tabriz University of Medical Sciences, Tabriz, IRAN; Akram Ghahramanian (ghahramaniana@ tbzmed.ac.ir), Assistant Professor, Department of Medical Surgical Nursing Nursing and Midwifery Faculty, Hematology and Oncology Research Center, Tabriz University of Medical Sciences, Tabriz, IRAN; Atefe Allahbakhshian (allahbakhshiana@tbzmed.ac.ir), Assistant Professor, Faculty of Nursing and Midwifery, Tabriz University of Medical Sciences, Tabriz, IRAN; Mozhgan Behshid (behshidm@tbzmed.ac.ir), Assistant Professor, Faculty of Nursing and Midwifery, Medical Education Research Centre, Tabriz University of Medical Sciences, Tabriz, IRAN.

To cite: Abdolmaleki M, Lakdizaji S, Ghahramanian A, Allahbakhshian A, Behshid M. Relationship between autonomy and moral distress in emergency nurses. Ind J Med Ethics. 2019 Jan-Mar:4(1)NS:20-5. DOI:10.20529/ IJME.2018.076.

Published online on October 6, 2018.

Manuscript Editor:Vijayaprasad Gopichandran

Peer reviewers: Kannan Thiruvengadam and C Priyadarshini

(c) Indian Journal of Medical Ethics 2018 hinders ethical reasoning, which may lead to moral distress. This descriptive correlation study investigates the relationship between professional independence and moral distress in 173 nurses working in emergency departments in Tabriz, Iran. Data were collected using questionnaires designed to assess professional autonomy and moral distress and analysed using descriptive and inferential statistics via the SPSS 13 software. The level of professional autonomy among emergency nurses was low (83.2 \pm 16.9$)$, and moral distress, moderate (7.43 \pm 3.52 ). A statistically significant negative relationship was reported between professional independence and the frequency of moral distress $(p=0.018)$. Bivariate analysis related professional autonomy with the frequency and intensity of moral distress. Multiple regression analysis showed that age significantly predicted moral distress (frequency, intensity, and total scores). Lack of autonomy hinders nurses from functioning effectively and efficiently in practice and even can lead to moral distress. Increasing professional independence and the use of experienced nurses as mentors in emergency settings to support younger nurses can help with the reduction of moral distress. 


\section{Introduction}

Autonomy is an important element of professional identity and quality of care in clinical practice. Professional independence in nursing has been defined as nurses' ability to make independent decisions based on sufficient knowledge, clinical expertise, and evidence-based practice (1). Reduction of nurses' autonomy can hinder nurses from making decisions, which can lead to moral distress (2). Invasive procedures, patients health conditions, resuscitation practice, and working with incompetent staff and policies that are in conflict with patients needs are challenges that nurses face in clinical practice (3).

Moral distress is defined as one type of discomfort that affects mind, body, and interpersonal relationships in the workplace. This is a result of conflict between what a person believes and how the person acts (4). In Jampton's view, moral tension arises when a person knows what the right thing to do is but is prevented from, and feels incapable of, doing it (5). A practical definition may be that moral distress is a painful feeling occurring when nurses are confronted with an action that is morally appropriate, but cannot do it because of institutional policies. Studies have shown that $80 \%$ of nurses experience moderate to high levels of moral distress in their working environments $(1,6)$. In a study by Corley, $15 \%$ of nurses left the profession because of moral tensions (6).

Common causes of moral distress among nurses are work pressure, high expectations of patients and their families, unnecessary examinations for patients, and the need for decision making about the final stages of life $(1,7)$. Moral tensions can have some adverse consequences for nurses and patients, including the loss of self-esteem, disappointment in professional life, reduced job satisfaction, burnout, and even giving up their career in nursing $(8,9)$.

Papathanassoglou et al (2) showed a converse relationship between the level of professional independence and moral distress among nurses working in intensive care units Ando and Kawano (10) reported that moral distress among psychiatric nurses was conversely related to their job satisfaction. Jacobson et al, in a study on the effects on moral/ emotional traits of workplace bullying in Master of Business Administration (MBA) students, found that moral/emotional traits could be useful during the staff's selection process (11). Additionally, age (3) and work experience (12) are other factors influencing emotional distress.

There is need for a professional method of dealing with professional dilemmas (13). Previous studies have focused on moral distress among nurses working in intensive care units, but we have surveyed the moral distress among nurses in emergency departments. Emergency nurses are exposed to more psychological and moral stresses due to the stressful atmosphere in the emergency room. The direct exposure of staff to patients and their relatives and patients' acute problems contribute to stressful situations (14). However there has been little evidence of the relationship between nurses' professional independence and moral distress in emergency nurses.
We hypothesised that professional independence has a relationship with moral distress among emergency nurses. This study was conducted to examine the relationship between professional independence and moral distress among nurses working in emergency departments.

\section{Methods}

\section{Participants and setting}

Astbury et al (15) declared that quantitative studies can measure and analyse the causal relationship between moral distress and associated variables. This descriptive correlation study was conducted in the emergency departments at five educational public hospitals in an urban area of Iran. The sample size was determined based on the findings of the Papathanassoglou study (2), the correlation between professional independence and moral distress (-0.21), with $95 \%$ confidence interval, $80 \%$ power and the bilateral test using the $\mathrm{G}$ power software version 3.0.10. Therefore, the samples estimated 178 individuals. However, considering 5\% drop out of samples, the final sample size was determined as 187 nurses. Therefore, 187 nurses working in emergency departments were selected using stratified sampling. The number of nurses from each hospital was selected proportional to the number of nurses working in the emergency department in each of the 5 hospitals. Nine subjects refused to continue the study, and five questionnaires were not completely filled out. Therefore, data from 173 nurses were considered for analysis.

Inclusion criteria were: 1) having a Bachelor's degree or higher qualification in nursing; 2 ) at least one year's experience in the emergency room; and 3) having attained the age of 22 years or above. Those nurses who had changed their workplace within the past six months were excluded from the study.

\section{Measurement tools}

The demographic data form consisted of questions on age, gender, marital status, work experience in the emergency room and income status. The original professional autonomy questionnaire which has been developed by Schutzenhofer to measure nurses' professional autonomy (16) was used in this study. It contained 30 items and used a four-point Likert scale of 1 to 5 . Total scores ranged from 30 to 150 . In this study for better presentation, we considered scores between 30 and 70 as low independence, 71 to 110 as moderate independence, and above 110 as higher independence. Its reliability, using the Cronbach's alpha coefficient, was reported as 0.94 .

Moral distress was measured using the Moral Distress ScaleRevised (MDS-R), which was revised by Ann Hamric based on Corley's original 38 item scale (17). The revised version had 21 items with a five-point Likert scale that measured the frequency and intensity of nurses' ethical tension (17). Higher scores indicated increased frequency and intensity of moral distress. In this study, we considered scores between 0 and 42 to indicate low frequency or intensity of moral tension; 43-84 moderate moral tension; and 85-126 higher intensity 


\begin{tabular}{|c|c|c|c|c|c|c|c|c|}
\hline \multicolumn{2}{|l|}{ Characters } & \multirow{3}{*}{\begin{tabular}{|l|}
$\mathbf{N}(\%)$ \\
$74(42.8)$ \\
$99(58.2)$ \\
\end{tabular}} & \multirow{3}{*}{$\begin{array}{l}\text { Autonomy* } \\
79.68(19.15) \\
85.82(14.55)\end{array}$} & \multirow{3}{*}{$\begin{array}{l}\mathbf{p} \\
0.183^{\alpha}\end{array}$} & \multicolumn{4}{|c|}{ Moral distress* } \\
\hline & & & & & \multirow{2}{*}{$\begin{array}{l}\text { frequency } \\
55.67(16.19) \\
45.77(11.80) \\
\end{array}$} & \multirow{2}{*}{$\begin{array}{l}\mathbf{p} \\
0.001^{\alpha}\end{array}$} & \multirow{2}{*}{\begin{tabular}{l|} 
intensity \\
$52.17(15.65)$ \\
$43.27(12.53)$
\end{tabular}} & \multirow{2}{*}{$\begin{array}{l}\mathbf{p} \\
<0.001^{\circ}\end{array}$} \\
\hline Age (years) & $\begin{array}{l}\leq 30 \\
>30\end{array}$ & & & & & & & \\
\hline Sex & $\begin{array}{l}\text { Male } \\
\text { Female }\end{array}$ & $\begin{array}{l}91(52.6) \\
82(47.4)\end{array}$ & $\begin{array}{l}85.06(13.72) \\
81.13(19.71)\end{array}$ & $0.134^{\alpha}$ & $\begin{array}{l}47.49(14.01) \\
49.32(16.80)\end{array}$ & $0.435^{\alpha}$ & $\begin{array}{l}47.80(14.08) \\
48.09(14.88)\end{array}$ & $0.407^{\alpha}$ \\
\hline Marital status & $\begin{array}{l}\text { Single } \\
\text { Married }\end{array}$ & $\begin{array}{l}72(41.6) \\
101(58.4)\end{array}$ & $\begin{array}{l}82.45(15.93) \\
83.73(17.61)\end{array}$ & $0.626^{\alpha}$ & $\begin{array}{l}50.43(15.70) \\
46.89(15.05)\end{array}$ & $0.136^{\alpha}$ & $\begin{array}{l}48.51(16.58) \\
47.53(12.73)\end{array}$ & $0.129^{\alpha}$ \\
\hline $\begin{array}{l}\text { Emergency } \\
\text { room work } \\
\text { experience } \\
\text { (years) }\end{array}$ & $\begin{array}{l}1-5 \\
6-10 \\
11-15 \\
16-20 \\
\geq 20 \\
\end{array}$ & $\begin{array}{l}107(61.8) \\
40(23.1) \\
12(6.9) \\
8(4.6) \\
6(3.5) \\
\end{array}$ & $\begin{array}{l}81.64(18.02) \\
84.27(14.20) \\
88.50(11.01) \\
81.25(21.02) \\
95.83(12.20) \\
\end{array}$ & $0.222^{\beta}$ & $\begin{array}{l}54.31(16.66) \\
44.80(10.42) \\
41.65(12.23) \\
43.50(16.82) \\
42.09(13.61)\end{array}$ & $0.001^{\beta}$ & $\begin{array}{l}51.12(15.96) \\
46.87(9.61) \\
46.35(12.33) \\
43.27(18.15) \\
40.72(13.48) \\
\end{array}$ & $0.062^{\beta}$ \\
\hline $\begin{array}{l}\text { Income } \\
\text { versus } \\
\text { expenditure }\end{array}$ & $\begin{array}{l}\text { On par } \\
\text { Expenditure in excess } \\
\text { Expenditure within income }\end{array}$ & $\begin{array}{l}63(36.4) \\
84(48.6) \\
26(15)\end{array}$ & $\begin{array}{l}80.80(13.03) \\
83.55(20.63) \\
87.84(9.58)\end{array}$ & $0.196^{\beta}$ & $\begin{array}{l}46.87(12.28) \\
49.19(17.20) \\
46.30(16.19)\end{array}$ & $0.630^{\beta}$ & $\begin{array}{l}45.71(14.08) \\
48.44(13.92) \\
51.73(16.36)\end{array}$ & $0.184^{\beta}$ \\
\hline
\end{tabular}

"Data presented as mean and standard deviation

${ }^{\alpha}$ independent $t$-test

${ }^{\beta}$ ANOVA

or frequency of moral distress. The reliability of the MDS-R using the calculation of the Cronbach's alpha coefficient was 0.88 (14). In the present study, the internal consistency was reported as 0.81 .

The validity of these questionnaires was confirmed by ten faculty members.

\section{Ethical considerations}

Prior to data collection, the aim and method of the study were explained to the participating nurses and informed consent was given by them. The ethics committee of the Tabriz University of Medical Sciences approved the study via approval number 1036514, dated August 31, 2017. Participation was optional, and the participants were assured that no identifying material would be collected from them.

\section{Data collection and analysis}

From April 2017 to June 2017, the questionnaires were given to the emergency nurses in different work shifts and they were asked to fill them out via the self-report method. Data analysis

\begin{tabular}{|l|l|l|l|}
\hline \multicolumn{5}{|c|}{ Table 2: } \\
Pearson Correlation significance between study variables ( $\mathbf{n}=173)$ \\
\hline Variables & Frequency & Intensity & Autonomy \\
\hline Frequency & 1 & $0.811^{* *}$ & $-0.328^{* *}$ \\
& & $(p<0.001)$ & $(p<0.001)$ \\
\hline Intensity & & 1 & $-0.180^{*}$ \\
& & & $(p=0.018)$ \\
\hline Total moral distress & & & $-0.269^{* *}$ \\
& & & $(p<0.001)$ \\
\hline Autonomy & & & 1 \\
\hline
\end{tabular}

* Correlation significant at the 0.05 level

** Correlation significant at the 0.01 level was performed using the SPSS 13 software. Demographic data, professional autonomy and moral distress were analysed through descriptive statistics (frequency, percentage, mean, and standard deviation). After evaluating and confirming the normality of data, correlations between professional autonomy and moral distress and demographic characters were analysed using the t-test, ANOVA, and Pearson correlation tests. The linear multivariate regression model was used to predict moral distress scores from contextual factors as autonomy scores were considered an independent variable.

\section{Results}

A total of 173 out of 187 distributed questionnaires were completed. Results are presented as per the different subscales.

\section{Demographic information of subjects}

The number of male nurses slightly exceeded that of female nurses $(52.6 \%$ and $47.4 \%$, respectively). Most of the subjects were under 30 years, married, and had experience of 1 to 5

Table 3: Predictors of the frequency of moral distress

\begin{tabular}{|c|c|c|c|c|c|c|}
\hline \multirow[t]{2}{*}{ Predictors } & \multicolumn{2}{|c|}{$\begin{array}{l}\text { Unstandardised } \\
\text { coefficient }\end{array}$} & \multirow{2}{*}{\begin{tabular}{|l}
$\begin{array}{l}\text { Standardised } \\
\text { Coefficient }\end{array}$ \\
Beta
\end{tabular}} & \multirow[t]{2}{*}{$p$} & \multicolumn{2}{|c|}{$95 \% \mathrm{Cl}^{*}$ for $\mathrm{B}$} \\
\hline & $B$ & \begin{tabular}{|l|}
$\begin{array}{l}\text { Standard } \\
\text { error }\end{array}$ \\
\end{tabular} & & & \begin{tabular}{|l|} 
Lower \\
bound \\
\end{tabular} & $\begin{array}{l}\text { Upper } \\
\text { bound }\end{array}$ \\
\hline Autonomy & -0.226 & 0.063 & -0.248 & $<0.001$ & -0.350 & -0.102 \\
\hline Age & -11.421 & 2.357 & -0.368 & $<0.001$ & -16.075 & -6.767 \\
\hline Gender & 2.520 & 2.117 & 0.082 & 0.236 & -1.660 & 6.699 \\
\hline $\begin{array}{l}\text { Work } \\
\text { experience in } \\
\text { emergency } \\
\text { nursing }\end{array}$ & -0.380 & 1.110 & -0.026 & 0.733 & -2.571 & 1.811 \\
\hline
\end{tabular}

"Confidence interval 


\begin{tabular}{|l|l|l|l|l|l|l|}
\hline \multicolumn{4}{|c|}{ Table 4: Predictors of the intensity of moral distress } & \multicolumn{2}{l|}{} \\
\cline { 1 - 5 } & Unstandardised coefficient & Standardised coefficient & \multirow{2}{*}{$\mathrm{p}$} & \multicolumn{2}{l|}{$95 \% \mathrm{Cl}^{*}$ for B } \\
\cline { 2 - 5 } & $\mathrm{B}$ & Standard error & Beta & & Lower bound & Upper bound \\
\hline Autonomy & -0.112 & 0.065 & -0.131 & 0.086 & -0.240 & 0.016 \\
\hline Age & -5.937 & 2.427 & -0.204 & 0.015 & -10.728 & -1.145 \\
\hline Gender & 0.599 & 2.180 & 0.021 & 0.784 & -3.705 & 4.902 \\
\hline Work experience in emergency nursing & -0.988 & 1.143 & -0.071 & 0.388 & -3.245 & 1.268 \\
\hline
\end{tabular}

* Confidence interval

years in emergency nursing. Most nurses indicated that their expenditure exceeded their income (Table 1).

\section{Professional autonomy}

The mean professional autonomy score of subjects was $83.20 \pm 16.89$, which indicates a low level of autonomy Professional autonomy scores vis-a-vis demographic are shown in Table 1. Data analysis using independent t-test and ANOVA showed no significant differences ( $p>0.05$ ) in autonomy scores based on demographic characters (Table 1).

\section{Moral distress}

The frequency and intensity of moral distress of emergency nurses were at moderate levels. The moral distress of participants based on demographic factors is shown in Table 1. Data analysis using independent t-test and ANOVA showed significant differences between frequency and intensity of moral distress based on age $(p=0.001)$ and work experience $(p<0.001)$ (Table 1).

\section{Relationship between professional autonomy and moral distress}

Bivariate analysis by the Pearson correlation coefficient between professional autonomy and moral distress is shown in Table 2. Professional autonomy had a significant relationship with frequency and intensity of moral distress $(p<0.01)$.

Three multiple regression analyses were run to predict moral distress scores (frequency and intensity) by sex, age, years of experience in emergency nursing, and autonomy scores.

In the first model for prediction of independent variables, autonomy and age significantly predicted moral distress frequency by $F(4,168)=13.525, p<0.001, R^{2}=0.244$. The proportion of variance in frequency of moral distress by these two predictors was $24.4 \%$. Unstandardised coefficient for autonomy was -0.226 (Table 3 ).
In the second model for prediction of independent variables, age significantly predicted the intensity of moral distress by $F$ $(4,168)=4.062, p=0.004, R^{2}=0.08$. The proportion of variance in moral distress intensity by age was $8 \%$. Unstandardised coefficient for autonomy was -0.112 . This means that for each one-point score increase in autonomy, there is a 0.112 score decrease in intensity of moral distress, all other independent variables considered constant (Table 4).

In the third model, for prediction of total moral distress from independent variables, age and autonomy significantly predicted it at $F(4,168)=8.911, p<0.001, R^{2}=0.175$. The proportion of variance in total moral distress was $17.5 \%$ and unstandardised coefficient for autonomy was -0.333 . This means that for each one-point score increase in autonomy, there is a 0.333 decrease in total moral distress, all other independent variables considered constant (Table 5). Based on the study hypothesis, professional autonomy had a significant negative correlation with moral distress.

\section{Discussion}

The findings of this study provided an initial figure of emergency nurses' autonomy and their moral distress. The mean of professional autonomy scores was low. The findings of the present study are in line with those in the study by Sarkoohijabalbarezi et al. (18). All the nurses in this study worked in emergency wards. However, studies on nurses working in intensive care settings and clinical nurses documented a higher level of nurse autonomy $(2,10,19-21)$.

Limiting the autonomy of nurses restricts their ability to decide and act in situations where quick and critical decisions are needed. When hospitals have no specific policies for addressing incidents of moral tension and conflict, it becomes difficult for nurses to make appropriate decisions and increases their distress. According to Mirsaidi et al, the low level of professional independence among nurses in Iran is related to obedience to doctors (22). The three most important factors that reduce nurses' autonomy are autocratic

\begin{tabular}{|l|c|c|c|c|c|c|c|}
\hline \multicolumn{9}{|c|}{ Table 5: Predictors of the total moral distress scores } \\
\hline \multirow{2}{*}{ Predictors } & Unstandardized Coefficients & Standardized Coefficients & \multirow{2}{*}{$\mathrm{t}$} & \multicolumn{2}{|c|}{$\mathrm{P}$} & \multicolumn{2}{c|}{$95 \% \mathrm{Cl}^{*}$ for B } \\
\cline { 2 - 6 } & $\mathrm{B}$ & Standard error & Beta & & & Lower Bound & Upper Bound \\
\hline Autonomy & -0.333 & 0.121 & -0.199 & -2.746 & 0.007 & -0.573 & -0.094 \\
\hline Age & -17.499 & 4.330 & -0.306 & -4.042 & $<0.001$ & -26.046 & -8.951 \\
\hline Gender & 3.270 & 4.056 & 0.058 & 0.806 & 0.421 & -4.738 & 11.279 \\
\hline Work experience in emergency nursing & -3.670 & 4.476 & -0.061 & -0.820 & 0.413 & -12.507 & 5.167 \\
\hline
\end{tabular}

* Confidence interval 
management (unnecessary interference), pressure on nurses to implement physicians' orders, and workload (23). The intensity and frequency of emotional distress among nurses in emergency settings was at a moderate level. This is in line with the results of other studies $(3,14,24)$ on moral distress in nurses. Alternatively, the results of the Papathanassoglou (2) study showed a low level of moral distress among nurses in intensive care units. Such a discrepancy in various studies can be attributed to different environments, work conditions, and unequal situations. It may be considered that nurses worry about professional errors. The more the tensions in the organisational environment, the higher the tensions perceived by staff, and consequently, the more the moral tensions.

Age had a negative and significant correlation with the frequency and intensity of moral distress. Borhani et al (4) showed that age and work experience had negative relationships with moral distress. Nurses use their own biological and psychological capacities to deal with moral distress. When nurses experience stress, they are more likely to quit their jobs. Some may even be pushed to give up nursing (25).

Nurses experience moral stress when they want to make ethical decisions in special situations. However, organisational barriers-such as the lack of adequate time, lack of supportive authority, physicians' superior authority, and policies and organisational rules-make it difficult for them to do the right thing, which creates moral distress among nurses.

There was a significant negative correlation between professional authority and frequency of moral distress. In other words, the greater the professional independence of nurses, the less moral tension they faced in emergency settings. These findings are in line with those of Karanikola et al in their study in intensive care units (20). Ameri et al (26) showed that professional independence of oncology nurses is one of the most important factors that reduced nurses' moral distress. Sarkoohijabalbarezi et al in a study in paediatric intensive care units found a positive correlation between nurses' professional autonomy and moral distress (18). They showed that increased professional autonomy without adequate support from physicians and relevant authorities was responsible for the positive relationship between professional autonomy and moral distress (18). Studies have shown that when nurses encounter the doctor-centred atmosphere of hospitals, it inhibits clinical decision-making by nurses, and requires absolute obedience to physicians' orders. So, nurses' lack of authority could lead to moral disturbances $(20,22)$. In this regard, Papathanassoglou et al showed collaboration scores were positively associated with autonomy scores. Lower levels of autonomy were associated with lower perceived nurse-physician collaboration (2). So, effective nurse-physician collaboration is imperative.

\section{Limitations}

This study was conducted on Iranian emergency nurses working in university hospitals. The level of nurses' authority and moral distress may be different in other departments and hospitals. While this study included nurses working in all areas-triage, resuscitation and outpatient care-each area should be studied in detail.

\section{Conclusions}

A negative relationship was found between professional autonomy and moral distress indicating more emotional distress when nurses' professional autonomy is compromised in emergency departments. When nurses are allowed to have greater independence to make decisions, the frequency and intensity of emotional distress is reduced. Therefore, it is recommended that support and interpersonal cooperation by nurse managers be increased and that experienced nurses should act as mentors to support younger nurses in emergency settings in order to reduce their moral distress.

\section{Conflicts of interest}

The authors declare no conflict of interest. There are no financial interests related to the materials of this study.

\section{Acknowledgments}

This article was the result of the Master's thesis in nursing of Mohsen Abdolmaleki, sponsored by Tabriz University of Medical Sciences. We acknowledge all nurses who participated in this study. Also we appreciate and sincerely thank Mrs. Nancy Mehler for editing this article in English.

\section{References}

1. Varjus SL, Suominen T, Leino-Kilpi H. Autonomy among intensive care nurses in Finland. Intensive Crit Care Nurs. 2003 Feb;19(1):31-40.

2. Papathanassoglou EDE, Karanikola MNK, Kalafati M, Giannakopoulou M Lemonidou C, Albarran JW. Professional autonomy, collaboration with physicians, and moral distress among European intensive care nurses. Am J Crit Care. 2012 Mar;21(2):e41-52.

3. Borhani F, Abbaszadeh A, Mohamadi E, Ghasemi E, Hoseinabad-Farahani MJ. Moral sensitivity and moral distress in Iranian critical care nurses. Nurs Ethics. 2017 Jun;24(4):474-82.

4. Borhani F, Mohammadi S, Roshanzadeh M. Moral distress and its relationship with professional stress in nurses. Iran J Med Ethics. 2014 Feb;6(6):10-9.

5. Jameton A. Dilemmas of moral distress: moral responsibility and nursing practice. AWHONNS Clin Issues Perinat Womens Health Nurs. 1993;4(4):542-51.

6. Corley MC. Nurse moral distress: a proposed theory and research agenda. Nurs Ethics. 2002 Nov;9(6):636-50.

7. Corley MC, Elswick RK, Gorman M, Clor T. Development and evaluation of a moral distress scale. J Adv Nurs. 2001 Jan;33(2):250-6.

8. Hart TJ. Moral distress in a non-acute continuing care setting: the experience of registered nurses [thesis]. Kingston, Ontario: Queen's University; 2009.

9. Bell J, Breslin JM. Healthcare provider moral distress as a leadership challenge. JONAS Healthc Law Ethics Regul. 2008 Oct-Dec;10(4):94-7.

10. Ando M, Kawano M. Association between moral distress and job satisfaction of Japanese psychiatric nurses. Asian/Pac Island Nurs J. 2016;1(2):55-60.

11. Jacobson RP, Hood JN, Jacobson KJL. The effects of moral emotional traits on workplace bullying perpetration. Ethics Behav. 2017;27(7):52746.

12. Hamric AB, Davis WS, Childress MD. Moral distress in health care professionals. Pharos Alpha Omega Alpha Honor Med Soc. 2006 Winter;69(1):16-23.

13. Chandra PS, Ragesh G, Chaturvedi SK. Ten-minute snapshots - a team approach to teaching postgraduates about professional dilemmas. Indian J Med Ethics. 2017 Apr;2(4):226-30. 
14. Fernandez-Parsons R, Rodriguez L, Goyal D. Moral distress in emergency nurses. J Emerg Nurs. 2013 Nov;39(6):547-52.

15. Astbury JL, Gallagher CT, O'Neill RC. Development of a tool to measure moral distress in community pharmacists. London: Pharmacy Research UK; 2014.

16. Schutzenhofer KK. The measurement of professional autonomy. J Prof Nurs. 1987 Sep-Oct;3(5):278-83.

17. Hamric $A B$, Borchers $C T$, Epstein EG. Development and testing of an instrument to measure moral distress in healthcare professionals. $A J O B$ Prim Res. 2012;3(2):1-9.

18. Sarkoohijabalbarezi Z, Ghodousi A, Davaridolatabadi E. The relationship between professional autonomy and moral distress among nurses working in children's units and pediatric intensive care wards. Int J Nurs Sci.2017 Jan;4(2):117-21.

19. Amini K, Negarandeh R, Ramezani Badr F, Moosaeifard M, Fallah R. Nurses' autonomy level in teaching hospitals and its relationship with the underlying factors. Int J Nurs Pract. 2015 Feb;21(1):52-9.

20. Karanikola MN, Albarran JW, Drigo E, Giannakopoulou M, Kalafati M, Mpouzika M, Tsiaousis GZ, Papathanassoglou ED. Moral distress, autonomy and nurse-physician collaboration among intensive care unit nurses in Italy. J Nurs Manag. 2014 May;22(4):472-84.

21. Lee HK, Yang HJ. Influence of professional self-concept and professional autonomy on nursing performance of clinic nurses. Int J Biosci Biotechnol. 2015;7(5):297-310.

22. Mirsaidi G, Lakdizaji S, Ghojazadeh M. How nurses participate in clinical decision- making process. J Appl Environ Biol Sci. 2012;2(12):620-4.

23. Mrayyan MT. Nurses' autonomy: influence of nurse managers' actions. $J$ Adv Nurs. 2004 Feb;45(3):326-36.

24. Azizi A,Sepahvani MA, Mohamadi J.Relationship between moral distress and mental health among female nurses. Iran J Nurs.2015 Feb;27(92):5764.

25. Abou Hashish EA. Relationship between ethical work climate and nurses' perception of organizational support, commitment, job satisfaction and turnover intent. Nurs Ethics. 2017 Mar 1;24(2):151-66.

26. Ameri M, Safavibayat Z, Kavousi A. [Evaluation of clinical situations leading to moral distress in nurses working in oncology wards of Tehranbased educational hospitals in 2012]. [Mod Care J]. 2014;11(2):153-60. Persian.

\section{ANNOUNCEMENT}

\section{Maiden Bioethics Essay Competition for 'IJME Young Bioethicist and Change-makers Award' by the Bioethics Centre, Forum for Medical Ethics Society, Mumbai}

We at Bioethics Centre, Forum for Medical Ethics Society, Mumbai, are pleased to announce the maiden Bioethics Essay Competition titled 'IJME Young Bioethicist and change-makers Award' aimed at creating spaces for young scholars to engage with bioethics matters and share their views with the larger peer community.

Who can submit essays?

Post graduate, MPhil and Doctoral students studying in India from a range of disciplines including Medicine, Nursing, Biomedical sciences, Public health, Health management, Law, Social sciences, Humanities, Journalism, and Engineering are welcome to submit essays.

Guidelines for essay writing:

Word count: About 1500 words;

Language: English;

Essay content: Innovative, thought provoking essays with fresh perspectives on the issue at hand will be preferred; Focus: Must centre-stage ethical, social, cultural and legal aspects;

Citation style: Must use a single citation style consistently through the essay; Type of file: Microsoft Word document and named as author's FirstName_LastName_DateofSubmission.docx;

Insertion of pictures: If any are inserted, must be sourced appropriately;

Inclusion of contact information: Must mention - Name, Postal Address, Contact number, Brief Bio-sketch in the covering email.

Timelines: (a) Essay submission: By midnight of March 21, 2019; (b)

Notification to winners: April, 2019;

Submit to: fmescentre.essay@gmail.com with a cover email explaining briefly (upto 200 words) your motivation for participating in the competition; Jury: Jury members will be drawn from the network of FMES and IJME.

Essay themes: (1) Health care professionals and the death penalty in India: Ethical obligations and challenges; (2) Ethical challenges and responsibilities in health journalism; (3) Artificial Intelligence in health care: Ethical and regulatory quandaries. [please visit www.ijme.in for more information] 